\title{
Survival Implications Associated with Variation in Mastectomy Rates for Early-Staged Breast Cancer
}

\author{
John M. Brooks, ${ }^{1}$ Elizabeth A. Chrischilles, ${ }^{2}$ Mary Beth Landrum, ${ }^{3}$ Kara B. Wright, ${ }^{2}$ \\ Gang Fang, ${ }^{4}$ Eric P. Winer, ${ }^{5}$ and Nancy L. Keating ${ }^{3,6}$ \\ ${ }^{1}$ College of Pharmacy, University of Iowa, Iowa City, IA 52242, USA \\ ${ }^{2}$ College of Public Health, University of Iowa, Iowa City, IA 52242, USA \\ ${ }^{3}$ Department of Health Care Policy, Harvard Medical School, Boston, MA 02115, USA \\ ${ }^{4}$ Eshelman School of Pharmacy, University of North Carolina, Chapell Hill, NC 27599, USA \\ ${ }^{5}$ Department of Medical Oncology, Dana Farber Cancer Institute, Boston, MA 02115, USA \\ ${ }^{6}$ Division of General Internal Medicine, Harvard Medical School, Brigham and Women's Hospital, \\ Boston, MA 02120, USA \\ Correspondence should be addressed to John M. Brooks, john-brooks@uiowa.edu
}

Received 23 March 2012; Revised 23 May 2012; Accepted 25 June 2012

Academic Editor: Steven Heys

Copyright (C) 2012 John M. Brooks et al. This is an open access article distributed under the Creative Commons Attribution License, which permits unrestricted use, distribution, and reproduction in any medium, provided the original work is properly cited.

\begin{abstract}
Despite a 20-year-old guideline from the National Institutes of Health (NIH) Consensus Development Conference recommending breast conserving surgery with radiation (BCSR) over mastectomy for woman with early-stage breast cancer (ESBC) because it preserves the breast, recent evidence shows mastectomy rates increasing and higher-staged ESBC patients are more likely to receive mastectomy. These observations suggest that some patients and their providers believe that mastectomy has advantages over BCSR and these advantages increase with stage. These beliefs may persist because the randomized controlled trials (RCTs) that served as the basis for the NIH guideline were populated mainly with lower-staged patients. Our objective is to assess the survival implications associated with mastectomy choice by patient alignment with the RCT populations. We used instrumental variable methods to estimate the relationship between surgery choice and survival for ESBC patients based on variation in local area surgery styles. We find results consistent with the RCTs for patients closely aligned to the RCT populations. However, for patients unlike those in the RCTs, our results suggest that higher mastectomy rates are associated with reduced survival. We are careful to interpret our estimates in terms of limitations of our estimation approach.
\end{abstract}

\section{Introduction}

Despite randomized controlled trial (RCT) evidence suggesting survival equivalence between breast conserving surgery with radiation (BCSR) and mastectomy for woman with early-stage breast cancer (ESBC) [1-5] and a nearly 20year-old guideline from the National Institutes of Health Consensus Development Conference recommending BCSR over mastectomy because it preserves the breast [6], mastectomy remains widely used $[7,8]$. In fact, recent evidence suggests that mastectomy rates are increasing $[7,9]$. In addition, higher-staged patients have been more likely to receive mastectomy $[8,10]$. These observations suggest that some patients and their providers believe that mastectomy has advantages over BCSR and these advantages increase with stage. These beliefs may persist because the randomized controlled trials (RCTs) that served as the basis for the NIH guideline were populated mainly with lower-staged, younger patients with few comorbidities [1-5].

In an analysis of the Surveillance, Epidemiology and End Results (SEER)-Medicare observational database [11] for ESBC patients using risk-adjustment methods, Keating et al. found no difference in mortality risk for mastectomy relative to BCSR for patients similar to those RCT samples (low-risk tumors-stage I, little comorbid illness, and age $\leq 70$ ) but higher average mortality risk across all ESBC patients [8]. 
These results imply a survival disadvantage for mastectomy in patients with larger tumors, more comorbid illnesses, or advanced age. In another risk-adjustment study using SEERMedicare data, Schonberg et al. found that mastectomy had a survival disadvantage relative to BCSR that increased with stage [10]. The risk-adjustment estimators used in both of these analyses only adjusted for measured covariates. For the estimates from these analyses to be unbiased it must be assumed that unmeasured covariates affecting surgery choice are unrelated to survival $[12,13]$. Keating et al. addressed this issue by assessing whether their results were robust to plausible imbalances in unmeasured covariates across surgery choices. This analysis found, at the very least, no evidence of a survival advantage associated with mastectomy.

Instrument variable (IV) estimators also are available to estimate treatment effectiveness using observational data. IV estimators are distinct from risk-adjustment estimators in both the assumptions required to yield unbiased estimates and in the interpretation of the eventual estimates [1418]. Risk-adjustment estimators assume that unmeasured covariates affecting treatment choice are unrelated to outcomes and yield parameters that are properly interpreted as estimates of the average treatment effectfor the patients that received treatment $[12-16,19,20]$. In contrast, IV estimators yield estimates of a local average treatment effect, that is, the average effect for the subset of patients whose treatment choices were affected by measured factors called "instruments" $[17,21,22]$. IV estimators require instruments with strong relationships with treatment choice [23]. IV estimators work under the assumption that the instruments used in the analysis have no direct effect on outcome and are independent of unmeasured covariates that affect outcome. Based on this assumption, IV estimators have been likened to natural experiments in treatment choice [24]. Previous IV studies assessed the effect of surgery choice for ESBC patients but were limited geographically, had small sample sizes, and used instruments with weak relationships with surgery choice which resulted in imprecise parameter estimates $[15,25,26]$. These pitfalls are avoided in this study by using the SEER-Medicare database that included ESBC patients from across the United States and by using an instrument that strongly predicts surgery choice. Our instrument exploits variation in local area physician practice styles that has been shown to be a practical and rich source for instrument development [15, 25, 27-31]. This approach conjectures that patients residing in areas with physicians that have preferences for a particular treatment are more apt to receive that treatment and that unmeasured confounding variables are unrelated to this access. Our algorithm to measure local area practice styles has been shown to explain a larger portion of treatment variation than other approaches and it effectively balances measured confounding variables $[31,32]$. Mastectomy rates vary significantly across the United States [8], suggesting that local area practice styles for ESBC patients vary regionally. From 1992-2002, mastectomy rates for ESBC patients were $40.4 \%$ in Connecticut, 59.2 in Utah, and $67.4 \%$ in Iowa [8].

\section{Materials and Methods}

2.1. Data and Sample. We used the 1992-2002 SEERMedicare databases and employed the same base inclusion/exclusion criteria used in the Keating study $[8,11]$. We identified 69,140 patients with stage I or II breast cancer that were enrolled in parts A and B of fee-forservice Medicare from 12 months before diagnosis through 9 months after diagnosis and had primary surgery (either breast conserving surgery or mastectomy). To compute local area mastectomy practice styles, we further excluded 1,005 patients that did not have a valid residence ZIP code, whose residence ZIP code was outside of a SEER area, or lived in an isolated island location within the Hawaii SEER registry. The remaining 68,135 patients were used to estimate local area mastectomy practice styles. Our dependent variable was 7-year survival after diagnosis, and our focus was comparing patients receiving mastectomy alone to those receiving BCSR. To estimate the effects of surgery choice on survival we further excluded patients with less than 7 years of followup $(N=32,683)$ and patients that either received BCS without radiation or mastectomy with radiation $(N=$ 6,777 ) leaving a final estimation sample of 28,675 patients. Models were also estimated using 6-year and 8-year survival as robustness checks for our estimates.

2.2. Instrumental Variable Approach. We estimated local area mastectomy practice styles using the driving area for clinical care (DACC) method [31, 32]. All ESBC patients with valid ZIP codes living in SEER areas $(N=68,135)$ were used. The DACC method produces ZIP-specific practice style measures that reflect the surgery choices for patients living within a driving distance of each ZIP code. For each patient residence ZIP code in the SEER-Medicare database, the DACC method expanded driving times around the ZIP code to add ESBC patients from additional ZIP codes until at least 50 patients were identified. For the set of patients associated with each ZIP code we then computed an area treatment ratio (ATR) as the ratio of the proportion of ESBC patients receiving mastectomy over the average predicted probability of the ESBC patients in the area to receive mastectomy. Predicted mastectomy probabilities for each patient were estimated using a multivariate logistic model of mastectomy choice over the 68,135 patients. The covariates used in this model are described in the variable specification section below. A ZIP code with an ATR greater than 1 suggests a local area practice style in which mastectomy is used at a rate higher than average given the characteristics of the ESBC patients in the area. An ATR less than 1 suggests a local area mastectomy practice style less than average. Our IV estimates rest on the assumption that the local area mastectomy practice style reflected by the ATR has no direct effect on survival other than through surgery choice and is unrelated to unmeasured covariates that affect survival. We assessed whether our results were robust to the number of ESBC patients used to define areas around ZIP codes by using 25 and 100-patient areas in separate analyses.

We applied the same two-stage least squares (2SLS) instrumental variable method used by the previous ESBC 
studies $[15,25,26,33]$ and the seminal IV study in health services research [34]. 2SLS yields consistent estimates regardless of the underlying error distributions in contrast to alternative estimators that rely on distributional assumptions which yield inconsistent results if the assumptions are wrong $[35,36]$. In the first stage of the 2SLS we estimated a model of mastectomy choice across the 28,675 patients with 7 years of followup that included, among other covariates described below, the ATR-based instrument as an independent variable. The instrument was specified in this first stage model using a series of binary variables for each patient that placed the patient's residence ZIP code ATR within the distribution of ATRs across ZIP codes. For example, four binary variables were constructed to represent the five ZIP code groups defined by quintile cutoffs of the ATRs across ZIP codes. Patients were then assigned values for these binary variables based on the ATR of their residence ZIP code relative to the cutoffs ( 1 if patient residence ATR is within respective cutoff points, zero otherwise). The second stage of the 2SLS method was the 7-year survival model which includes all the non-instrument covariates from the first-stage model as independent variables plus the predicted mastectomy choice from the first stage. As a result of this 2-stage process, the parameter estimate associated predicted mastectomy choice in the second stage will be estimated using only the variation in mastectomy choice associated with the ATR instrument. Under the IV assumption, this estimated parameter provides a consistent estimate of the effect of mastectomy on survival.

To assess the robustness of our findings to alternative specifications, 2SLS models were run with the instrument specified using median, quintile, decile, and vigintile cutoffs of ATR values. 2SLS models were also estimated using the full sample and for patient subsets defined by stage, age, and the alignment of patients with clinical trial eligibility. In addition, we estimated a Hausman test statistic [37] for each 2SLS specification. 2SLS models in which the instrument is specified using more than two groups are also said to be overidentified and a Hausman test statistic can be estimated to test the null hypothesis of whether the patient groups identified using the instrument have no empirical relationship with survival beyond the effect of the instruments on surgery choice. A large value of the Hausman statistic rejects the null hypothesis. We also produced riskadjustment estimates using linear probability models to provide a link between the risk-adjustment estimates from previous research and our IV estimates from the 2SLS estimator.

2.3. Variable Definitions. The multivariate logistic mastectomy choice model used as the basis for ATR estimation included patient covariates age at diagnosis, race, Hispanic ethnicity, marital status, diagnosis year, cancer history, tumor stage, tumor size, tumor grade, histology, estrogen and progesterone receptor status, comorbid illness, adjuvant chemotherapy use, and residence area average characteristics (education, income, and living in a metropolitan area). Characteristics of the hospital and physician were also specified. All covariates above were specified consistently with the Keating study and a full description of covariate measurement can be found there [8]. The dependent variable in 2SLS and linear probability models was a binary variable indicating 7 -year survival after diagnosis ( 1 if patient survives 7 years, 0 otherwise). Surgery choice was defined using a binary variable ( 1 if patient received mastectomy, 0 if the patient received BCSR) based on accepted definitions using Medicare claims data [38-41]. In addition to the covariates above, the 2SLS and linear probability models also specified as covariates the proportion of ESBC patients that received breast conserving surgery alone and proportion of patients that received mastectomy plus radiation in the DACCdefined area around each patient residence ZIP code, and binary variables for each SEER area. These covariates were added to control for differences in the mix of ESBC patients not receiving mastectomy alone and BCSR across areas.

\section{Results}

Table 1 contains summary statistics for the estimation sample by surgery (BCSR versus mastectomy) choice and by the quintiles of the local area mastectomy practice style measure. Relative to patients choosing BCSR, mastectomy patients were generally older and sicker with higher-staged disease, larger tumors, a higher percentage of poorly differentiated tumors, and they had more comorbid conditions. In addition, patients receiving mastectomy were more apt to see physicians with lower surgical volume, be treated in smaller hospitals, live in nonmetro areas, and live in areas with lower area median per capita income. In contrast, there were few clear relationships between the patients grouped by the ATR measure of local area mastectomy practice style and measured covariates. From quintile 1 to quintile 5, the percentage of patients receiving mastectomy increases from $37.9 \%$ to $68.6 \%$. While variation in the measured covariates is observed across the instrument-based quintile groups, these differences mostly do not trend with the mastectomy percentages across groups. Cochran-Armitage trend tests show statistically significant trends across the instrument groups only for moderate tumor grade, unknown tumor grade, hospital size, residence metro status, and area median income $[42,43]$.

Figures $1(\mathrm{a})$ and $1(\mathrm{~b})$ contain maps showing mastectomy practice styles as measured by the area treatment ratios (ATRs) across SEER areas over the period 1992-2002. Clearly, substantial geographic variation in surgical choice for ESBC patients exists after controlling for differences in measured patient and provider characteristics. While some SEER-area specific variation is visible (e.g., Connecticut with few high mastectomy areas), both high and low mastectomy areas exist within each SEER area.

Table 2 contains estimates of the effect on 7-year survival of mastectomy relative to BCSR. The table contains both linear probability and IV estimates of the average 7-year survival effect of mastectomy relative to BCSR. As discussed above, these IV estimates are average mastectomy survival effects for those patients whose surgery choices would have differed had they lived in an area with a different local area mastectomy practice style. Table 2 contains IV estimates from the quintile instrument specification. Estimates from 
TABLE 1: Early-stage breast cancer patient characteristics by surgery choice and instrumental variable-based patient quintile groups.

\begin{tabular}{|c|c|c|c|c|c|c|c|c|c|c|c|}
\hline \multirow{3}{*}{ Variable } & \multicolumn{2}{|l|}{ Covariates } & \multicolumn{3}{|c|}{ Surgery choice } & \multicolumn{6}{|c|}{$\begin{array}{l}\text { Instrument quintile groups } \\
(\text { higher area treatment ratio }(\text { ATR }) \rightarrow \text { ) }\end{array}$} \\
\hline & \multirow[t]{2}{*}{ Category } & \multirow[t]{2}{*}{ Total } & BCSR & Mastectomy & $\begin{array}{l}P \text { value } \\
\left(\chi^{2}\right)^{\mathrm{a}}\end{array}$ & 1 & 2 & 3 & 4 & 5 & $\begin{array}{l}P \text { value } \\
\left(\chi^{2}\right)^{\mathrm{b}}\end{array}$ \\
\hline & & & \multicolumn{3}{|c|}{ Column \% } & \multicolumn{5}{|c|}{ Column \% } & \\
\hline \multirow{2}{*}{ Surgery } & Mastectomy & $16,103(56 \%)$ & 0 & $100 \%$ & \multirow{2}{*}{ na } & 37.9 & 50.2 & 59.7 & 65.7 & 68.6 & $<0.0001^{*}$ \\
\hline & BCSR & $12,572(44 \%)$ & $100 \%$ & $0 \%$ & & 62.1 & 49.8 & 40.3 & 34.3 & 31.4 & $<0.0001^{*}$ \\
\hline \multirow{2}{*}{ Age } & $66-75$ & $16,442(57 \%)$ & 63.9 & 52.2 & \multirow{2}{*}{$<0.0001^{*}$} & 57.8 & 58.0 & 56.2 & 57.4 & 57.3 & 0.2251 \\
\hline & $76+$ & $12,233(43 \%)$ & 36.1 & 47.8 & & 42.2 & 42.0 & 43.8 & 42.6 & 42.7 & 0.2251 \\
\hline \multirow{4}{*}{ Stage at diagnosis } & Stage I & $17,908(62 \%)$ & 75.1 & 52.6 & \multirow{4}{*}{$<0.0001^{*}$} & 63.8 & 62.0 & 62.4 & 60.8 & 63.2 & 0.0908 \\
\hline & Stage IIa & $7,700(27 \%)$ & 20.1 & 32.1 & & 25.7 & 27.5 & 26.7 & 27.8 & 26.6 & 0.1261 \\
\hline & Stage IIb & 2,827 (10\%) & 4.4 & 14.1 & & 9.7 & 9.6 & 10.1 & 10.6 & 9.3 & 0.4096 \\
\hline & Stage IInos & $240(1 \%)$ & 0.4 & 1.2 & & 0.8 & 0.9 & 0.8 & 0.8 & 0.9 & 0.2169 \\
\hline \multirow{4}{*}{ Tumor size } & $\leq 10$ & $8,797(31 \%)$ & 40 & 23.4 & \multirow{4}{*}{$<0.0001^{*}$} & 31.3 & 30.3 & 30.0 & 29.9 & 31.9 & 0.3633 \\
\hline & $11-20$ & $11,958(42 \%)$ & 43.4 & 40.3 & & 42.1 & 41.8 & 42.5 & 40.8 & 41.4 & 0.1152 \\
\hline & $>21$ & $7,680(27 \%)$ & 16.2 & 35.1 & & 25.8 & 27.1 & 26.7 & 28.5 & 25.8 & 0.2090 \\
\hline & unknown & $240(1 \%)$ & 0.4 & 1.2 & & 0.8 & 0.9 & 0.8 & 0.8 & 0.9 & 0.2169 \\
\hline \multirow{4}{*}{ Grade } & Well differentiated & $4,751(17 \%)$ & 20.7 & 13.4 & \multirow{4}{*}{$<0.0001^{*}$} & 16.4 & 17.0 & 16.0 & 16.1 & 17.4 & 0.2426 \\
\hline & Moderately differentiated & $10,804(38 \%)$ & 39.9 & 35.9 & & 39.3 & 38.4 & 37.3 & 36.6 & 36.6 & $0.0002^{*}$ \\
\hline & Poorly differentiated & $6,718(23 \%)$ & 20.3 & 25.9 & & 23.1 & 22.4 & 24.4 & 24.6 & 22.6 & 0.2138 \\
\hline & Undifferentiated/unknown & $6,402(22 \%)$ & 19.1 & 24.9 & & 21.2 & 22.1 & 22.3 & 22.7 & 23.3 & $0.0031^{*}$ \\
\hline \multirow[t]{2}{*}{ Comorbidity } & Below median & $15,784(55 \%)$ & 58.1 & 52.7 & \multirow{2}{*}{$<0.0001^{*}$} & 54.6 & 55.7 & 54.7 & 56.0 & 54.1 & 0.3759 \\
\hline & Above median & $12,891(45 \%)$ & 41.9 & 47.3 & & 45.4 & 44.3 & 45.3 & 44.0 & 45.9 & 0.3759 \\
\hline \multirow{2}{*}{$\begin{array}{l}\text { Physician surgical } \\
\text { volume }\end{array}$} & Low volume & $8,510(30 \%)$ & 26.0 & 32.6 & \multirow{2}{*}{$<0.0001^{*}$} & 27.5 & 33.2 & 30.3 & 29.2 & 28.4 & 0.1447 \\
\hline & High volume & $20,165(70 \%)$ & 74.0 & 67.4 & & 72.5 & 66.8 & 69.7 & 70.9 & 71.6 & 0.1447 \\
\hline \multirow[t]{2}{*}{ Hospital bed size } & $\leq 350$ & $15,461(54 \%)$ & 52.6 & 54.9 & \multirow[t]{2}{*}{$<0.0001^{*}$} & 54.8 & 57.7 & 56.8 & 52.1 & 47.9 & $<0.0001^{*}$ \\
\hline & $351+$ & $13,214(46 \%)$ & 47.4 & 45.1 & & 45.2 & 42.3 & 43.2 & 47.9 & 52.1 & $<0.0001^{*}$ \\
\hline \multirow[t]{2}{*}{ Residence area size } & Metro & $24,530(86 \%)$ & 90.7 & 81.5 & \multirow{2}{*}{$<0.0001^{*}$} & 91.0 & 87.8 & 78.8 & 77.4 & 92.7 & $<0.0001^{*}$ \\
\hline & Nonmetro & $4,145(14 \%)$ & 9.3 & 18.5 & & 9.0 & 12.2 & 21.2 & 22.6 & 7.3 & $<0.0001^{*}$ \\
\hline \multirow{3}{*}{ Area median income } & Above median & $14,483(51 \%)$ & 53.9 & 47.8 & \multirow{3}{*}{$<0.0001^{*}$} & 52.4 & 51.9 & 41.8 & 50.2 & 56.3 & $0.0032^{*}$ \\
\hline & Below median & $13,730(48 \%)$ & 44.6 & 50.4 & & 46.9 & 46.3 & 57.3 & 46.6 & 42.2 & $0.0001^{*}$ \\
\hline & Missing & $462(2 \%)$ & 1.5 & 1.7 & & 0.7 & 1.8 & 0.9 & 3.2 & 1.5 & $<0.0001^{*}$ \\
\hline
\end{tabular}

${ }^{\mathrm{a}}$ Test of difference in characteristic distribution between surgery choices.

${ }^{\mathrm{b}}$ Cochran-Armitage test of trend in characteristic value across patients grouped into quintiles based on local area mastectomy practice style measure. For example, the $P$ value for stage I tests whether a linear trend in stage I diagnoses exists across the instrument-based patient groups.

$* P<0.05$.

the other instrument specifications are comparable in magnitude and statistical significance and are available from the authors upon request. Our linear probability estimates for the full sample and for the patient subsets by trial status alignment are consistent with earlier risk-adjustment model findings. Mastectomy has a statistically significant negative impact on 7-year survival for the full sample, but this negative effect appears to be stem mainly from the subset of patients unlike those in the clinical trials. Higher-staged and older patients had higher mastectomy rates and the negative effect of mastectomy on survival estimates increase with stage and age.

The Chow-test [44] F-values in Table 2 test whether the binary variables representing the ATR instrument in the firststage regression of 2 SLS describe a statistically significant portion of the variation in mastectomy choice. Instruments with a Chow-test $F$-statistic less than 10 are considered "weak" in the IV literature [23]. Our Chow-test F-statistics 


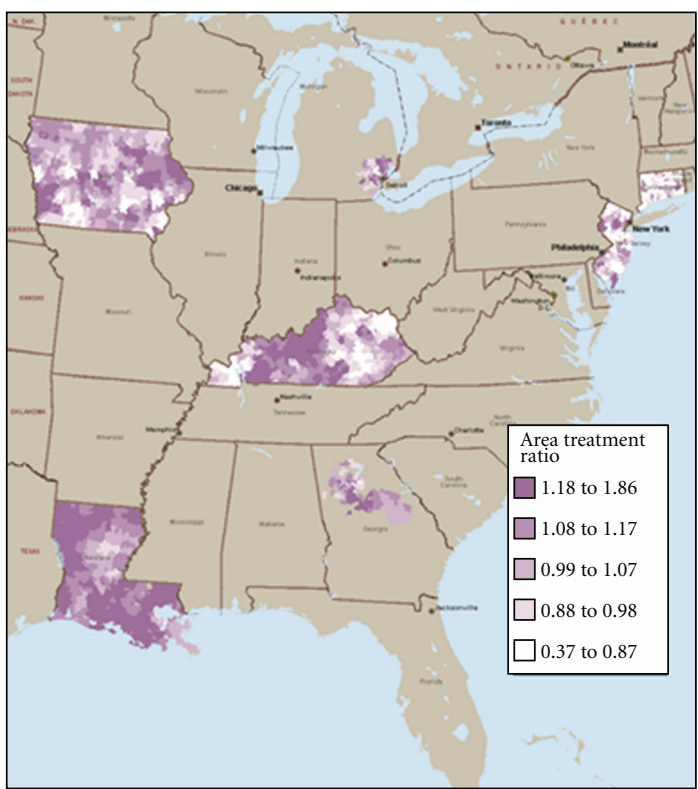

(a)

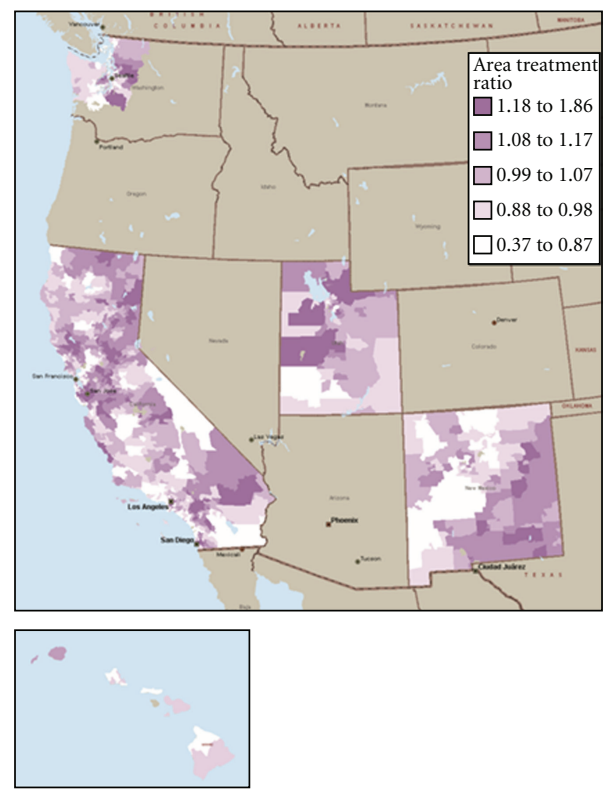

(b)

FiguRE 1: Zip-code level maps of mastectomy local area treatment ratios for SEER areas in the eastern United States.

are much larger than 10 for both the full-sample and for all-patient subsets. Based on the Hausman statistic, the null hypothesis of whether the patient groups identified using the ATR instrument have no relationship with survival beyond the effect of the instruments on surgery choice was maintained for the full sample and all patient subsets. The 2SLS estimate of the effect of mastectomy on survival for the entire sample was negative, statistically significant, and greater in magnitude than the estimate from the linear probability model. As with the linear probability estimate, the IV estimate for patients aligned with those in the clinical trials revealed no relationship between surgery choice and survival. The negative relationship between mastectomy and survival stems mainly from patients unlike those in trials whose IV estimate is negative and statistically significant. These estimates suggest that a 1 percentage point increase in the mastectomy rate for the patients unlike those in the trial populations would reduce the 7-year survival rate by .1 percentage points. When looking at patient subsets across stage and age groups, the negative impact of mastectomy on survival appears to increase with both age and stage with statistically significant negative relationships between mastectomy use and survival for patients with stage IIa tumors and patients 81 and older. In addition, the estimates in Table 2 are robust to the number of patients used to define treatment areas around each patient ZIP code $(25$ or 100 ) and whether 6-year or 8-year survival was used as an endpoint. The estimates from these robustness checks are available from the authors.

\section{Discussion}

Substantial regional variation in mastectomy rates for patients with early stage breast cancer (ESBC) has been documented. We used the portion of mastectomy rate variation for ESBC patients 66 and older that was unrelated to measured covariates as a measure of local area mastectomy style. The survival implications associated with variation in local area mastectomy practice style for ESBC patients 66 and older were estimated in an instrumental variable (IV) analysis. In general, IV estimators produce estimates which represent the average effects of treatment on outcomes for the subset of patients whose treatment choices were influenced by the instrument specified in the analysis. Because IV estimates are specific to patients whose treatment choices are affected by the specified instrument, methodologists have cautioned about generalizing these results too broadly and making inferences using IV estimates for policy questions unrelated to the specified instrument [45]. In this paper our local area mastectomy practice style instrument is directly aligned to the policy question of whether higher mastectomy rates affect the survival of ESBC patients.

Our IV estimates suggest that higher mastectomy rates described by differences in local area mastectomy practice styles were associated with reduced survival relative to BCSR for ESBC patients 66 and older. These estimates are consistent with the risk-adjustment estimates from linear probability models but are slightly larger. The existing NIH guideline does not mention the possibility of mastectomy survival disadvantages relative to BCSR. It suggests only that for most ESBC patients mastectomy and BCSR are equivalent with respect to survival and that mastectomy may offer advantages for higher-staged patients. However, recent evidence on radiation effectiveness from meta-analyses of controlled trials and observational studies suggests that radiation may have greater survival benefits for ESBC patients than what was presented in the original trials [46-48]. Our IV estimates support the notion that radiation provides 
TABLE 2: Estimates of the effect of mastectomy relative to breast conserving surgery with radiation on 7-year survival by estimator and sample subsets ${ }^{1}$.

\begin{tabular}{|c|c|c|c|c|c|c|}
\hline \multirow{3}{*}{$\begin{array}{l}\text { Estimation } \\
\text { Sample }\end{array}$} & \multirow{3}{*}{$N$} & \multirow{3}{*}{$\begin{array}{c}\text { Mastectomy } \\
\text { percentage } \\
\text { (1st-5th quintile } \\
\text { range) }\end{array}$} & \multicolumn{4}{|c|}{ Estimator } \\
\hline & & & \multirow{2}{*}{$\begin{array}{l}\text { Linear probability estimates }^{2} \\
\text { Mastectomy effect on } 7 \text {-year } \\
\text { survival (std. error) }\end{array}$} & \multicolumn{3}{|c|}{ Instrumental variable estimates ${ }^{3}$} \\
\hline & & & & $\begin{array}{c}\text { Instrument } \\
\text { chow test }[44] \\
F \text {-value }\end{array}$ & $\begin{array}{c}\text { Over } \\
\text { identification } \\
\text { test } F \text {-value }\end{array}$ & $\begin{array}{c}\text { Mastectomy effect } \\
\text { on 7-year survival } \\
\text { (std. error) }\end{array}$ \\
\hline Full sample & 28,675 & $\begin{array}{c}56.2 \\
(37.9-68.6)\end{array}$ & $\begin{array}{c}-0.030^{*} \\
(0.006)\end{array}$ & $264.01^{*}$ & 0.60 & $\begin{array}{c}-0.071^{*} \\
(0.029)\end{array}$ \\
\hline \multicolumn{7}{|c|}{ Trial status comparable ${ }^{4}$} \\
\hline Yes & 5,003 & $\begin{array}{c}43.5 \\
(25.5-57.0)\end{array}$ & $\begin{array}{l}-0.001 \\
(0.010)\end{array}$ & $50.43^{*}$ & 0.57 & $\begin{array}{c}0.05 \\
(0.05)\end{array}$ \\
\hline No & 23,672 & $\begin{array}{c}58.8 \\
(40.4-71.1)\end{array}$ & $\begin{array}{c}-0.037^{*} \\
(0.006)\end{array}$ & $215.60^{*}$ & 0.38 & $\begin{array}{c}-0.10^{*} \\
(0.03)\end{array}$ \\
\hline \multicolumn{7}{|l|}{ Stage } \\
\hline Stage I & 17,908 & $\begin{array}{c}47.3 \\
(28.2-61.3)\end{array}$ & $\begin{array}{c}-0.017^{*} \\
(0.006)\end{array}$ & $174.75^{*}$ & 0.93 & $\begin{array}{l}-0.02 \\
(0.03)\end{array}$ \\
\hline Stage IIa & 7,700 & $\begin{array}{c}67.2 \\
(50.3-78.5)\end{array}$ & $\begin{array}{c}-0.049^{*} \\
(0.011)\end{array}$ & $63.02^{*}$ & 1.28 & $\begin{array}{c}-0.15^{*} \\
(0.06)\end{array}$ \\
\hline Stage IIb & 2,827 & $\begin{array}{c}80.2 \\
(66.4-88.7)\end{array}$ & $\begin{array}{c}-0.085^{*} \\
(0.023)\end{array}$ & $23.81^{*}$ & 2.03 & $\begin{array}{l}-0.22 \\
(0.13)\end{array}$ \\
\hline \multicolumn{7}{|l|}{ Age } \\
\hline $66-70$ & 8,037 & $\begin{array}{c}50.9 \\
(33.5-64.3)\end{array}$ & $\begin{array}{l}-0.010 \\
(0.009)\end{array}$ & $75.53^{*}$ & 1.99 & $\begin{array}{c}0.02 \\
(0.05)\end{array}$ \\
\hline $71-75$ & 8,405 & $\begin{array}{c}51.4 \\
(31.4-64.1)\end{array}$ & $\begin{array}{l}-0.016 \\
(0.010)\end{array}$ & $81.82^{*}$ & 0.15 & $\begin{array}{l}-0.05 \\
(0.05)\end{array}$ \\
\hline $76-80$ & 6,611 & $\begin{array}{c}57.5 \\
(39.9-71.2)\end{array}$ & $\begin{array}{c}-0.049^{*} \\
(0.012)\end{array}$ & $69.94^{*}$ & 0.42 & $\begin{array}{l}-0.11 \\
(0.06)\end{array}$ \\
\hline $81+$ & 5,622 & $\begin{array}{c}69.2 \\
(52.3-78.6)\end{array}$ & $\begin{array}{c}-0.065^{*} \\
(0.015)\end{array}$ & $37.15^{*}$ & 1.06 & $\begin{array}{c}-0.19^{*} \\
(0.09)\end{array}$ \\
\hline
\end{tabular}

${ }^{1}$ All models also specified all measured covariates listed in the variable definition section and are more fully described in Keating et al. [8].

${ }^{2}$ Average treatment effect on the treated (ATT). In this case, average effect of mastectomy on 7-year survival for those patients choosing mastectomy.

${ }^{3}$ Local average treatment effect (LATE). The average effect of mastectomy on 7-year survival for those patients whose mastectomy choice would have changed with local area mastectomy practice style.

${ }^{4}$ ESBC patients with low-risk tumors (stage I), little comorbid illness, and age $\leq 70$.

${ }^{*} P<0.05$.

greater survival benefits than was originally anticipated from the trial data especially for older patients with more severe disease who are unlike those patients in the original trials. In addition, it is has been shown that many BCSR patients fail to complete their adjuvant radiation therapy [49] which suggests that our results may understate the benefits of BCSR with a completed radiation course.

Of course, the inferences that can be made from our estimates depend on the validity of the assumptions underlying our estimators. Risk-adjustment estimators assume that unmeasured covariates related to surgery choice are unrelated to survival after controlling for measured covariates. It is clear from the comparison of measured covariates in Table 1 that the ESBC patients in our study that received mastectomy tended to have higher-staged disease, less welldifferentiated tumors, and more comorbid conditions and were older. These relationships suggest that other unmeasured factors related to disease severity such as tumor location may be positively correlated with mastectomy choice. If true, our risk-adjustment estimators may be biased against mastectomy. Keating et al. showed that within plausible relationships of unmeasured confounders and surgery choice, though, that a mastectomy survival advantage cannot be supported from these data.

Our IV estimates of the effect of mastectomy on survival are consistent if the measure of local area mastectomy practice style we used as an instrument has no direct effect on survival and is unrelated to other unmeasured 
factors affecting survival. As seen in Table 1, grouping ESBC patients based on local area mastectomy practice style clearly reduces the differences in measured confounders as compared to grouping patients by surgery choice. While some differences in measured covariates remained across the patients grouped by our instrument, few substantial trends remained across groups. However, it remains possible that patients grouped by local area mastectomy practice style are different in unmeasured ways that are associated with survival such as access to quality healthcare services. For example, if patients living in high mastectomy areas have less access to quality healthcare services, our IV estimates of the effect of mastectomy on survival biased be a biased low (more negative) estimated of the true effect for the ESBC patients whose surgery choices would vary with local area mastectomy practice style. Readers should also be cautioned about generalizing our IV estimates to the ESBC patients whose surgery choices would not have varied with the mastectomy practice style in the area they lived. For example, of the ESBC patients not aligned with the trial populations over $40 \%$ received mastectomy and nearly $29 \%$ received BCSR regardless of where they lived. This suggests there are ESBC patients that all providers believe are best-suited to a particular surgery choice regardless of the provider's practice style. Because our sample was limited to patients aged 66 and older, readers should also be cautioned about generalizing our results to younger patients.

\section{Conclusions}

The randomized controlled trial evidence that led to the guideline conclusion of survival equivalence between mastectomy and breast conserving surgery with radiation (BCSR) for patients with early-staged breast cancer (ESBC) included mainly younger, stage I patients with few comorbid conditions. As a result, a paucity of evidence is available to judge the relative effectiveness of ESBC surgery choices for patients unlike those in the trials. Observed surgery choices suggest that many providers and patients believe that mastectomy is superior to BCSR for older and higherstaged patients. However, there is no evidence to support or reject these beliefs. In this paper we were able to describe the relationship between surgery choice and survival for ESBC patients aged 66 and older by exploiting the tremendous amount of variation in local area mastectomy practice styles. Our results suggest that reducing the mastectomy rate in favor of BCSR may yield positive survival gains for higherstaged older ESBC patients. These results are probably bestapplied to questions associated with changes in surgery rates across populations, and readers are cautioned about generalizing these results to all ESBC patients. Additional studies are needed to confirm these results. Future studies based on observational data should include chart abstraction components for a sample of patients to assess the validity of the assumptions underlying the estimators used. Additional controlled trials among patients unrepresented in the original ESBC controlled studies may be needed to confirm these results.

\section{Acknowledgments}

Funded by the National Cancer Institute, Grant R01 CA104118. Iowa investigators were also partially funded by an Agency for Healthcare Research and Quality (AHRQ) Centers for Education and Research on Therapeutics cooperative Agreement no. 5 (U18 HSO16094). This study used the linked SEER-Medicare database. The interpretation and reporting of these data are the sole responsibility of the authors. The authors acknowledge the efforts of the Applied Research Program, NCI; the Office of Research, Development and Information, CMS; Information Management Services (IMS), Inc.; the Surveillance, Epidemiology, and End Results (SEER) Program tumor registries in the creation of the SEER-Medicare database. The authors would like to acknowledge the valuable programming assistance of Rita Volya, M.S. In addition, the collection of the California cancer incidence data used in this study was supported by the California Department of Public Health as part of the statewide cancer reporting program mandated by California Health and Safety Code Section 103885; the National Cancer Institute's Surveillance, Epidemiology and End Results Program under Contract N01-PC-35136 awarded to the Northern California Cancer Center, contract N01-PC-35139 awarded to the University of Southern California, and Contract N02-PC-15105 awarded to the Public Health Institute; the Centers for Disease Control and Prevention's National Program of Cancer Registries, under Agreement no. U55/CCR921930-02 awarded to the Public Health Institute. The ideas and opinions expressed herein are those of the author(s) and endorsement by the State of California, Department of Public Health the National Cancer Institute, and the Centers for Disease Control and Prevention or their Contractors and Subcontractors is not intended nor should be inferred.

\section{References}

[1] R. Arriagada, M. G. Lê, F. Rochard, and G. Contesso, "Conservative treatment versus mastectomy in early breast cancer: patterns of failure with 15 years of follow-up data," Journal of Clinical Oncology, vol. 14, no. 5, pp. 1558-1564, 1996.

[2] U. Veronesi, A. Banfi, B. Salvadori et al., "Breast conservation is the treatment of choice in small breast cancer: long-term results of a randomized trial," European Journal of Cancer, vol. 26, no. 6, pp. 668-670, 1990.

[3] B. Fisher, S. Anderson, C. K. Redmond, N. Wolmark, D. L. Wickerham, and W. M. Cronin, "Reanalysis and results after 12 years of follow-up in a randomized clinical trial comparing total mastectomy with lumpectomy with or without irradiation in the treatment of breast cancer," The New England Journal of Medicine, vol. 333, no. 22, pp. 1456-1461, 1995.

[4] J. A. Jacobson, D. N. Danforth, K. H. Cowan et al., "Ten-year results of a comparison of conservation with mastectomy in the treatment of stage I and II breast cancer," The New England Journal of Medicine, vol. 332, no. 14, pp. 907-911, 1995.

[5] J. A. van Dongen, A. C. Voogd, I. S. Fentiman et al., "Longterm results of a randomized trial comparing breastconserving therapy with mastectomy: European organization for research and treatment of cancer 10801 trial," Journal of the National Cancer Institute, vol. 92, no. 14, pp. 1143-1150, 2000. 
[6] NIH Consensus Conference, "Treatment of early-stage breast cancer," The Journal of the American Medical Association, vol. 265, pp. 391-397, 1991.

[7] T. M. Tuttle, E. B. Habermann, E. H. Grund, T. J. Morris, and B. A. Virnig, "Increasing use of contralateral prophylactic mastectomy for breast cancer patients: a trend toward more aggressive surgical treatment," Journal of Clinical Oncology, vol. 25, no. 33, pp. 5203-5209, 2007.

[8] N. L. Keating, M. B. Landrum, J. M. Brooks et al., "Outcomes following local therapy for early-stage breast cancer in nontrial populations," Breast Cancer Research and Treatment, vol. 125, no. 3, pp. 803-813, 2011.

[9] R. Katipamula, A. C. Degnim, T. Hoskin et al., "Trends in mastectomy rates at the Mayo Clinic Rochester: effect of surgical year and preoperative magnetic resonance imaging," Journal of Clinical Oncology, vol. 27, no. 25, pp. 4082-4088, 2009.

[10] M. A. Schonberg, E. R. Marcantonio, D. Li, R. A. Silliman, L. Ngo, and E. P. McCarthy, "Breast cancer among the oldest old: tumor characteristics, treatment choices, and survival," Journal of Clinical Oncology, vol. 28, no. 12, pp. 2038-2045, 2010.

[11] A. L. Potosky, G. F. Riley, J. D. Lubitz, R. M. Mentnech, and L. G. Kessler, "Potential for cancer related health services research using a linked Medicare-tumor registry database," Medical Care, vol. 31, no. 8, pp. 732-748, 1993.

[12] D. B. Rubin, "The central role of the propensity score in observational studies for causal effects," Biometrika, vol. 70, no. 1, pp. 41-55, 1983.

[13] D. B. Rubin, "Estimating causal effects from large data sets using propensity scores," Annals of Internal Medicine, vol. 127, no. 8, pp. 757-763, 1997.

[14] J. D. Angrist, "Treatment effect heterogeneity in theory and practice," The Economic Journal, vol. 114, no. 494, pp. C52C83, 2004.

[15] J. M. Brooks and E. A. Chrischilles, "Heterogeneity and the interpretation of treatment effect estimates from risk adjustment and instrumental variable methods," Medical Care, vol. 45, no. 10, pp. S123-S130, 2007.

[16] J. M. Brooks and G. Fang, "Interpreting treatment-effect estimates with heterogeneity and choice: simulation model results," Clinical Therapeutics, vol. 31, no. 4, pp. 902-919, 2009.

[17] J. J. Heckman, S. Urzua, and E. Vytlacil, "Understanding instrumental variables in models with essential heterogeneity," The Review of Economics and Statistics, vol. 88, no. 3, pp. 389432, 2006.

[18] G. Fang, J. M. Brooks, and E. A. Chrischilles, "Apples and oranges? Interpretations of risk adjustment and instrumental variable estimates of intended treatment effects using observational data," American Journal of Epidemiology, vol. 175, no. 1, pp. 60-65, 2012.

[19] J. J. Heckman, "Econometric causality," International Statistical Review, vol. 76, no. 1, pp. 1-27, 2008.

[20] J. J. Heckman and R. Robb, "Alternative methods for evaluating the impact of interventions," in Longitudinal Analysis of Labor Market Data, J. J. Heckman and B. Singer, Eds., pp. 156245, Cambridge University Press, New York, NY, USA, 1985.

[21] J. D. Angrist, G. W. Imbens, and D. B. Rubin, "Identification of causal effects using instrumental variables," Journal of the American Statistical Association, vol. 91, no. 434, pp. 444-472, 1996.
[22] G. W. Imbens and J. D. Angrist, "Identification and estimation of local average treatment effects," Econometrica, vol. 62, no. 2, pp. 467-475, 1994.

[23] D. Staiger and J. H. Stock, "Instrumental variables regression with weak instruments," Econometrica, vol. 65, no. 3, pp. 557586, 1997.

[24] J. D. Angrist and A. B. Krueger, "Instrumental variables and the search for identification: from supply and demand to natural experiments," Journal of Economic Perspectives, vol. 15, no. 4, pp. 69-85, 2001.

[25] J. M. Brooks, E. A. Chrischilles, S. D. Scott, and S. S. ChenHardee, "Was breast conserving surgery underutilized for early stage breast cancer? Instrumental variables evidence for stage II patients from Iowa," Health Services Research, vol. 38, no. 6, pp. 1385-1402, 2003.

[26] J. Hadley, D. Polsky, J. S. Mandelblatt et al., "An exploratory instrumental variable analysis of the outcomes of localized breast cancer treatments in a medicare population," Health Economics, vol. 12, no. 3, pp. 171-186, 2003.

[27] J. M. Brooks, M. McClellan, and H. S. Wong, "The marginal benefits of invasive treatments for acute myocardial infarction: does insurance coverage matter?" Inquiry, vol. 37, no. 1, pp. 75-90, 2000.

[28] M. A. Brookhart, P. S. Wang, D. H. Solomon, and S. Schneeweiss, "Evaluating short-term drug effects using a physician-specific prescribing preference as an instrumental variable," Epidemiology, vol. 17, no. 3, pp. 268-275, 2006.

[29] J. A. Rassen, M. A. Brookhart, R. J. Glynn, M. A. Mittleman, and S. Schneeweiss, "Instrumental variables II: instrumental variable application-in 25 variations, the physician prescribing preference generally was strong and reduced covariate imbalance," Journal of Clinical Epidemiology, vol. 62, no. 12, pp. 1233-1241, 2009.

[30] T. A. Stukel, E. S. Fisher, D. E. Wennberg, D. A. Alter, D. J. Gottlieb, and M. J. Vermeulen, "Analysis of observational studies in the presence of treatment selection bias: effects of invasive cardiac management on AMI survival using propensity score and instrumental variable methods," The Journal of the American Medical Association, vol. 297, no. 3, pp. 278-285, 2007.

[31] G. Fang, J. M. Brooks, and E. A. Chrischilles, "Comparison of instrumental variable analysis using a new instrument with risk adjustment methods to reduce confounding by indication," American Journal of Epidemiology, vol. 175, no. 11, pp. 1142-1151, 2012.

[32] G. Fang, J. M. Brooks, and E. A. Chrischilles, "A new method to isolate local-area practice styles in prescription use as the basis for instrumental variables in comparative effectiveness research," Medical Care, vol. 48, no. 8, pp. 710-717, 2010.

[33] A. Basu, J. J. Heckman, S. Navarro-Lozano, and S. Urzua, "Use of instrumental variables in the presence of heterogeneity and self-selection: an application to treatments of breast cancer patients," Health Economics, vol. 16, no. 11, pp. 1133-1157, 2007.

[34] M. McClellan, B. J. McNeil, and J. P. Newhouse, "Does more intensive treatment of acute myocardial infarction in the elderly reduce mortality? Analysis using instrumental variables," The Journal of the American Medical Association, vol. 272, no. 11, pp. 859-866, 1994.

[35] J. D. Angrist, "Estimation of limited dependent variable models with dummy endogenous regressors: simple strategies for empirical practice," Journal of Business \& Economic Statistics, vol. 19, no. 1, pp. 2-16, 2001. 
[36] J. D. Angrist and J.-S. Pischke, Mostly Harmless Econometrics: An Empiricist's Companion, Princeton University Press, Princeton, NJ, USA, 2009.

[37] J. A. Hausman, "Specification and estimation of simultaneous equation models," in Handbook of Econometrics, Z. Griliches and M. D. Intriligator, Eds., vol. 1, pp. 392-448, NorthHolland, New York, NY, USA, 1983.

[38] G. S. Cooper, B. A. Virnig, C. N. Klabunde, N. Schussler, J. L. Freeman, and J. L. Warren, "Use of SEER-Medicare data for measuring cancer surgery," Medical Care, vol. 40, supplement 8, pp. IV43-IV48, 2002.

[39] X. Du, J. L. Freeman, and J. S. Goodwin, "Information on radiation treatment in patients with breast cancer: the advantages of the linked Medicare and SEER data," Journal of Clinical Epidemiology, vol. 52, no. 5, pp. 463-470, 1999.

[40] N. L. Keating, M. B. Landrum, J. Z. Ayanian, E. P. Winer, and E. Guadagnoli, "Consultation with a medical oncologist before surgery and type of surgery among elderly women with earlystage breast cancer," Journal of Clinical Oncology, vol. 21, no. 24, pp. 4532-4539, 2003.

[41] N. L. Keating, M. B. Landrum, E. Meara, P. A. Ganz, and E. Guadagnoli, "Do increases in the market share of managed care influence quality of cancer care in the fee-for-service sector?" Journal of the National Cancer Institute, vol. 97, no. 4, pp. 257-264, 2005.

[42] W. G. Cochran, "Some methods of strengthening the common chi-squared tests," Biometrics, vol. 10, pp. 417-451, 1954.

[43] P. Armitage, "Tests for linear trends in proportions and frequencies," Biometrics, vol. 11, pp. 375-386, 1955.

[44] G. Chow, "Tests of equality between sets of coeffiecients in two linear models," Econometrica, vol. 28, no. 3, pp. 591-605, 1960.

[45] J. J. Heckman, "Building bridges between structural and program evaluation approaches to evaluating policy," Journal of Economic Literature, vol. 48, no. 2, pp. 356-398, 2010.

[46] O. Abe, R. Abe, K. Enomoto et al., "Effects of radiotherapy and of differences in the extent of surgery for early breast cancer on local recurrence and 15-year survival: an overview of the randomised trials," The Lancet, vol. 366, no. 9503, pp. 20872106, 2005.

[47] B. D. Smith, B. G. Haffty, A. Hurria, D. H. Galusha, and C. P. Gross, "Postmastectomy radiation and survival in older women with breast cancer," Journal of Clinical Oncology, vol. 24, no. 30, pp. 4901-4907, 2006.

[48] T. A. Buchholz, W. A. Woodward, Z. Duan et al., "Radiation use and long-term survival in breast cancer patients with $\mathrm{T} 1$, T2 primary tumors and one to three positive axillary lymph nodes," International Journal of Radiation Oncology Biology Physics, vol. 71, no. 4, pp. 1022-1027, 2008.

[49] T. P. Srokowski, S. Fang, Z. Duan et al., "Completion of adjuvant radiation therapy among women with breast cancer," Cancer, vol. 113, no. 1, pp. 22-29, 2008, Cancer, vol. 113, no. 9, pp. 2615. 




The Scientific World Journal
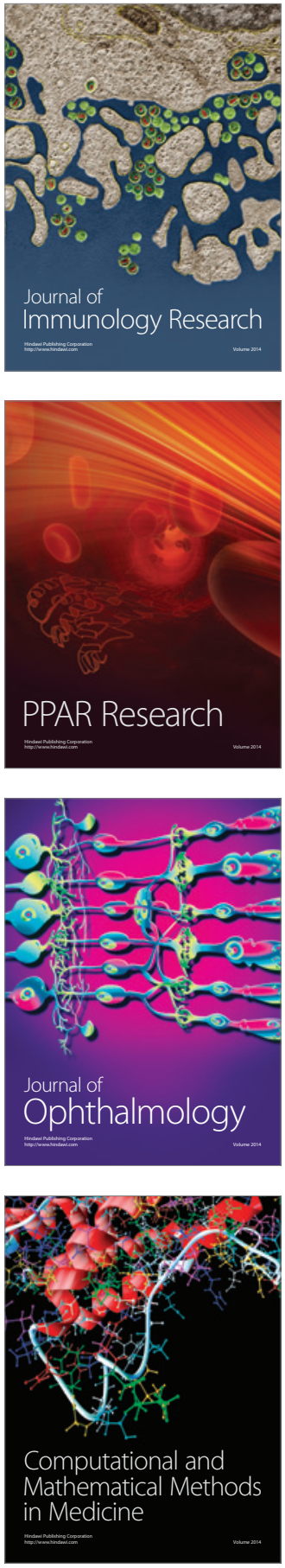

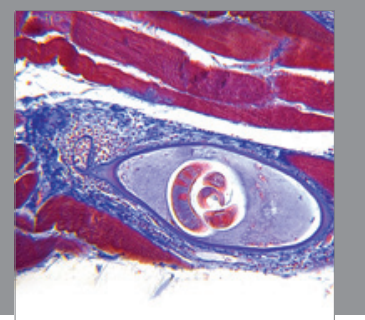

Gastroenterology

Research and Practice
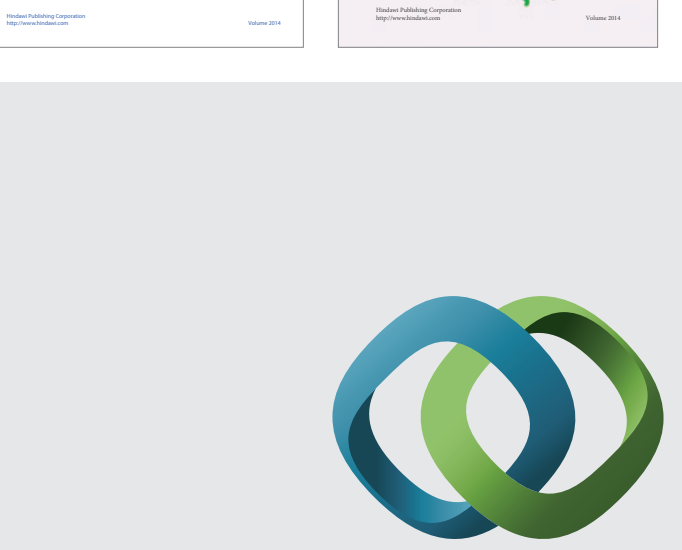

\section{Hindawi}

Submit your manuscripts at

http://www.hindawi.com
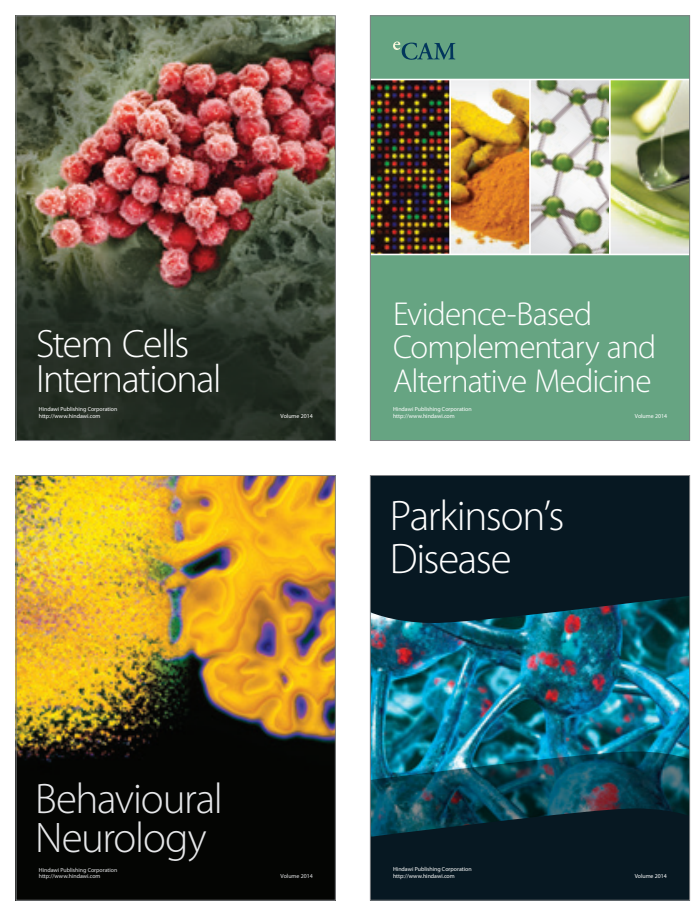

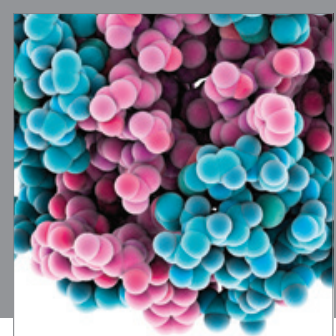

Journal of
Diabetes Research

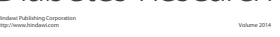

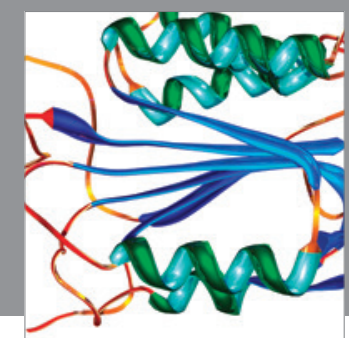

Disease Markers
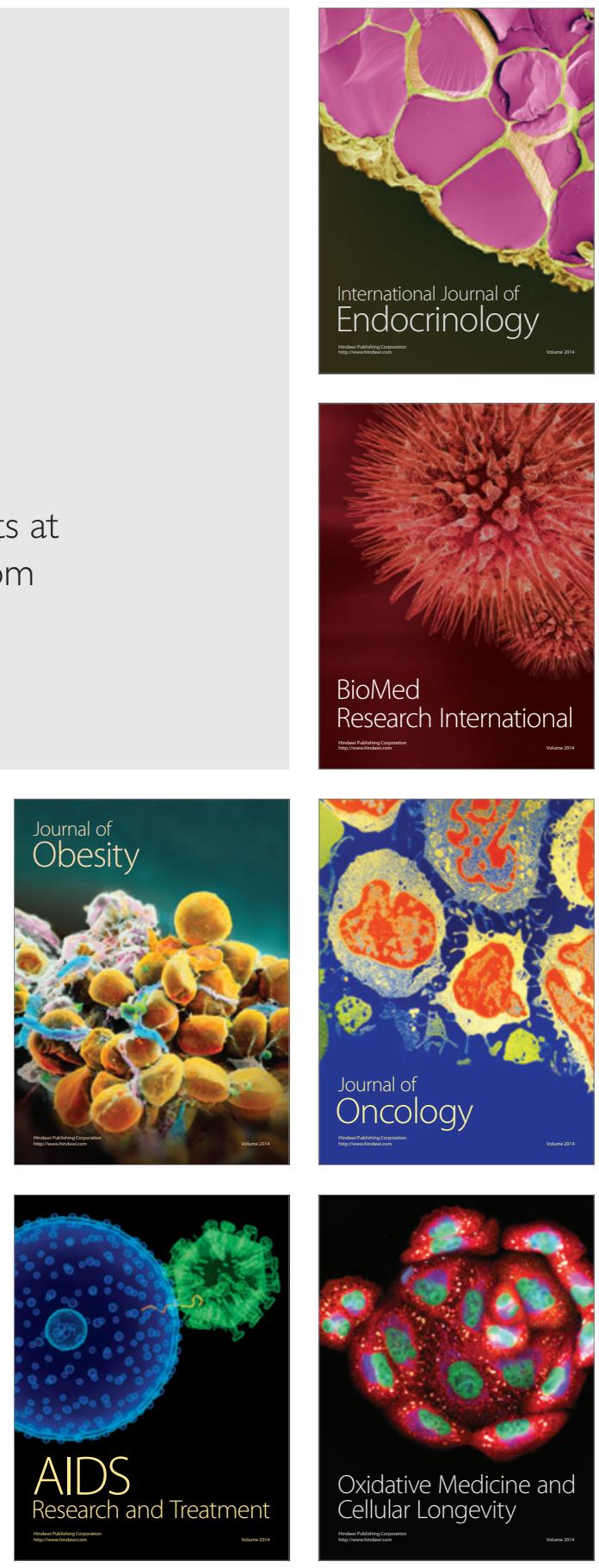